\title{
Cultural Values' Dimensions of Tambak Lorok Fisheries Community
}

\author{
Nurhayati ${ }^{1}$, Agus Subiyanto ${ }^{2}$ \\ \{noerhytwid@yahoo.com ${ }^{1}$, agussubiyanto@live.undip.ac.id $\left.{ }^{2}\right\}$ \\ Department of Linguistics, Faculty of Humanities, Diponegoro University \\ J1. Prof. Soedarto, S.H. Undip Tembalang, Semarang, Central Java - Indonesia, 50275
}

\begin{abstract}
This study is about categorizing Tambak Lorok fisheries community based on the cultural values they share. The community is unique because even though they live in suburb area near metropolis city, based on the observation, the social practice articulated by the community show that there is influence of the traditional Javanese values. This interests us to do serious research, because the finding will be benefit for making policy regarding their social roles. Data are text produced by five informants selected randomly. To collect the data, depth interview is used. The result shows that Tambak Lorok fisheries community tends to be the community that are harmonious, collective, hierarchical, and have high power distance. This is different from the cultural values shared by general fisheries communities. This may be influenced by the valued shared by the Javanese community in general. The abstract needs to summarize the content of the paper.

Keywords: cultural values dimensions; small-scale fisheries community; Javanese
\end{abstract}

\section{Introduction}

The fast increase of technological development in the fourth industrial revolution era has an impact on many aspects of social life, including human attitude. People give different response to the social change. Some may adapt the condition, so that they change their way of life, leaving their previous values. Some others may change certain values and maintain the other ones. However, there are also people that are not influenced by the social change, and keep the values that have guided their life from generation. The way people response the social change may be reflected through their discourse practice. As mentioned by Fairclough ${ }^{[1]}$, in producing discourse, people are conditioned by not only linguistic non-rules, but also socio-cultural constraints, such as norms, values, and knowledge that control the society of which the people are members.

Considering the close relationship between discourse practice and its context, it is interesting in exploring the cultural values shared by a society through the discourse of their members. In this study, the researchers concern to explain the cultural values shared by the members of the fisheries community in Tambak Lorok area. Some studies regarding the fisheries societies show that the small-scale fishing communities have similar cultures as a result of their adaptation to marine ecosystem ${ }^{[2]},{ }^{[3]}$. They are also open communities, meaning that they are adaptive to other cultures. On the other hand, research regarding the relationship between cultural values and environmental adaptation showed that cultural values are products of their adaptation and exploitation ${ }^{[4]}$. Based on the explanation, there is assumption that members of the Tambak Lorok fisheries community do the social practices that reflect the 
adaptive and open culture using certain shared cultural values as a control. This studi needs to know their shared knowledge regarding the nature, their social, economic, political, and religious organization, and their adaptation to global culture. It will help other people to understand them and cooperate with them. It is also significant for the government or the policy maker, because it is necessary to understand the cultural values of the community before they apply policies to the community.

\section{Method}

The subjects of the study are members of the small-scale fisheries community living in Tambak Lorok, North Semarang. The Tambak Lorok fishing community are Javanese people who work as fishermen or families of fishermen who live in Tambak Rejo village, Semarang. Data of the research are texts produced by the five informants representing all levels of adult community members. To collect the data, we conducted indepth interview to the five informants using concepts of cultural dimension from Hofstede as a guideline ${ }^{[5]}$. In the interview, the researchers let the informants produce narratives to express their idea. The cultural values of the fisheries were expressed explicitly or implicitly. Therefore, the researchers used the concepts of explicature and implicature to analyze the data. As mentioned previously, when producing texts, a speaker will measure information owned by his/her interlocutor. When a speaker assumes that certain information is generally known by people, he or she may presuppose it, rather than expressing explicitly. They may also implicitly or indirectly express the general information based on the assumption that the information is shared generally ${ }^{[6]}$. In this case, the researchers used the concept of presupposition to identify the cultural values that were assumed as common knowledge by the informants. Data were analyzed using Hofstede's cultural dimensions, those are individualism vs. collectivism, masculinity vs. femininity, power distance, and uncertainty avoidance ${ }^{[5]}$ and Shwartz ${ }^{[7] .}$ The analyzed data were then compared to the general characteristics of small-scale fisheries communities found by McGoodwin ${ }^{[2]}$. As a part of broader community, McGoodwin ${ }^{[2]}$ argued the fisheries communities are open communities that politically, economically, and socially are shaped by other values in constructing the organization. They are categorized as non- fishing specialist, that do not catch fish during the whole year, and the motivation of fishing is merely to fulfill the family need, rather than for commercial purposes. However, they are proud identified as fishers with characteristics as self-reliance and risk taking persons. Fishing is not merely for fulfilling their daily needs, but as representing their identity.

\section{Result and Discussion}

Using the parameters of cultural dimensions proposed by Hofstede ${ }^{[5]}$, the researchers found that Tambak Lorok Fisheries community is a community that is hierarchical, collective, embedded, masculine, restrain, and harmonious. Other characteristics are accepting uncertain condition and keeping status quo. The deep discussion of the above characteristics can be seen in the following explanation.

First, the Tambak Lorok fishing community is a community that accepts an unequal division of power. The Tambak Lorok fishing community has shared knowledge of groups that have the capital to control economic activities, namely ship owners, capital owners, and 
buyers of catches. The group has the capacity to regulate the role of individuals in fishing groups, daily workers on land, and when fishermen have to go home in order to sell their catches. Communities that do not have capital become coolies both at sea and on land. This unequal relationship becomes communal knowledge agreed upon in the community as reasonable knowledge.

Second, the Tambak Lorok fishing community is one that emphasizes collectivity. The characteristics of collectivity are shown by an attitude that attaches importance to the familiarity and retention of traditions that have been carried out from year to year. Religious events are not merely the praxis of vertical relations between humans and the Creator, but also a means to build togetherness. The easy attitude of forgiveness, high awareness of the mistakes of others, and better silence are manifestations of the values of collectivity that they hold. In addition, the practice of maintaining tradition is an effort to maintain togetherness.

Third, the Tambak Lorok fishing community is a community that avoids uncertainty. The value of avoiding this uncertainty is indicated by the less courage of Tambak Lorok fishermen in taking risks in trying something new, such as changing fishing tools, colliding with migrant communities that have the potential to cause conflict, and changing professions other than as fishermen. Another manifestation of this characteristic feature of the community is the attitude of accepting the situation as it is. They are grateful for whatever they face and accept. This can be seen from how they respond to the catch. They don't feel angry or disappointed when they get a little catch, and are not proud and arrogant when they get a lot of catch. They assume that fortune has been arranged by God, so whatever they receive must always be grateful. With this attitude, their lives are quite calm and not overwhelmed with envy or hurt against fellow fishermen. This attitude also makes the atmosphere of harmony between fishermen possible. The attitude of accepting this situation is also seen in their motivation to work as fishermen. For most fishermen, working as fishermen is something that must be accepted because they assume there is no other choice in working other than as fishermen. This surrender makes them less interested in other jobs, which for them require various adjustments. They feel comfortable with the conditions they face and accept, even though they often get inadequate income. The attitudes have in common with the general characteristics of small-scale fishing communities in developing countries, namely: (1) only a small proportion of fishermen work throughout the year, (2) their existence is influenced by the global economy, (3) the existence of very strong kinship relations between them [2].

Fourth, the Tambak Lorok fishing community is a masculine society. They have shared knowledge about the division of labor and responsibility based on gender differences. For the community, working as fishermen in the sea is a man's job. Activities at sea are very heavy and very risky, so they are only done by men. Father is the head of the family who is responsible for fulfilling all the needs of family members and in charge of finding fish in the sea, while the mother is responsible for raising children and selling fish catches. Men's social organizations are oriented towards improving welfare in the economic sector, while women's social organizations are oriented towards improving the quality of children and helping men, rather than taking over the responsibilities of men. Women in the fisheries communities have double tasks, doing households and processing, marketing, and distributing fish.

Fifth, the Tambak Lorok fishing community is a community that has a short-term orientation that only acts for short-term interests, namely the interests faced at that time, not the interests that will be faced by their children and grandchildren. They do not encourage their children to become fishermen because at this time being a fisherman is a hard job with mediocre income. The generation of fishermen now and their successors do not think about the sustainability of fishing communities in the Tambak Lorok area. 
Sixth, the is able to control themselves and wants to be controlled by other parties. The community is easily adapted to outsiders. Various government regulations relating to the use of fishing gear are always adhered to, even though that does not benefit them. Following rules is the attitude put forward, rather than protesting against a policy.

Seventh, the community upholds harmony, shown by religious tolerance, maintaining natural balance, and harmony with others. They are generally Muslim and have a high tolerance for followers of other religions. This can be seen from a very harmonious life between them, both among followers of the Islamic religion or with adherents of other religions, both from the local community and the immigrant community. A harmonious life is also reflected in social activities, such as regular meetings that discuss various social issues, such as recitation meetings, neighborhood meetings (RT). This shows that the community has a very high togetherness value. The harmony is also indicated by a passive attitude in the face of change. They tend to accept what employment opportunities and fortune they get. They do not want to try more because they are principled that fortune already exists.

Eight, the fishing community is generally adaptive to changes in nature and the environment. This can be seen in their attitude towards seasonal changes and the availability of fish in the sea. There are certain seasons, such as the Kewolon season (the 8th season in the Javanese calendar), where they will go fishing and get lots of fish. However, there are also certain seasons, such as the Pura ura season (strong winds) where they do not go to sea because there are not many fish. The adaptive attitude of fishermen is also evident from changes in fishing grounds. The arrival of large ships, such as cantrang in their area, made the availability of fish very limited, and even they often did not get fish in the shallow places they used to go through. However, this does not reduce their enthusiasm for fishing in the sea, because they think that there are fish in the sea. For that, they moved to the middle of the sea to find fortune in fishing using Sopek boat. Although fishermen are adaptive to the natural environment, they are less adaptive to new technologies. The arrival of new technologies such as millennium nets, which are considered to have advantages compared to ordinary nets (nylon nets), are less acceptable for various reasons. First, they consider that the millennium net is quite expensive, so they are reluctant to spend money to buy the net. Second, they are still difficult to adapt to the use of the millennium net. In addition, they assume that with ordinary nets they can still get fish. Their old habits are using arat nets (tiger trawlers), which the government has banned, they cannot stop. They feel comfortable with their old habits, even though they conflict with government regulations. This shows that changes in working patterns to adjust to new technology, are still being done. Even the government's efforts to provide training in the use of millennium nets have not produced significant results.

In addition to the above characteristics, some cultural characteristics of Tambak Lorok fishing community show the characteristics of the general small-scale fishing communities [2]. They are open and adaptive. The adaptation and exploitation are represented in their religious belief, ritual, cultural values, and other social practice. On the other hand, other cultural aspects of Tambak Lorok fishing community is different from small-scale fishermen in general [2]. Tambak Lorok fishermen are generally not interested in other jobs other than as fishermen, so their economic level is almost the same. This is different from the characteristics of small-scale fishermen in general who can have different economic levels depending on their interest or motivation in part-time work other than as fishermen [2]. This difference in attitudes is also related to the Javanese culture of the Tambak Lorok fishing community who have the attitude of accepting the situation as it is, so they are quite difficult to accept changes. Another difference between the Tambak Lorok fishing community and small-scale fishermen generally lies in the motivation to find fish. In the Tambak Lorok community, the purpose of 
fishing is to get money from the sale of fish (commercial purposes), and they spend the money to buy daily necessities. This is different from the motivation of small-scale fishermen in general who have non-commercial goals in fishing. Generally they are looking for fish to be eaten or exchanged for goods from their neighbors. They do not bring fish to the market for commercial purposes.

\section{Conclusion}

From the results of the analysis, it can be concluded that Tambak Lorok fishing community tends to emphasize the value of harmony and collectivism rather than mastery and individual. This value is reflected in the behavior of religiosity, community, and work. The community prioritizes harmonious condition, so that if there is a problem that creates social friction among their members or between the community and the other, they tend to solve through communication. This value is different from universal values in the small-scale fishing communities in general, which tend to be aggressive. The harmony and collective values reflect the value of the Javanese community, rather than the fishing community.

Other cultural values possessed by the community are hierarchy and a high-power distance. This means that the community accepts shared knowledge that there is a power hierarchy that is not equal. They naturally accept that a wider society is governed by groups or institutions that have capital. The rules set by the authorities are accepted as a consequence of the conditions of the hierarchical society. They obey the rules set by both the government and investors. This value is also a reflection of the cultural values possessed by Javanese society in general. Regarding the hierarchical value, Tambak Lorok fishing community also shows an embedded value instead of being autonomous. This value is reflected in their attitude that depends heavily on nature and tradition. They are passive and accept the consequences of social change in society and changes in nature. They also have an attitude of avoiding uncertainty, so they prefer stability, rather than trying something new that contains risks.

\section{References}

[1] N. Fairclough, Language and Power ( $2^{\text {nd }}$ edition), Longman Publisher, New York (2001)

[2] R. Goodwin, S.Giles, Journal of Cross-Cultural Psychology. Social support provision and cultural values in Indonesia and Britain. 34, 2 (2003)

[3] N. Kuruppu, Environmental Science and Policy. Adapting water resources to climate change in Kiribati: the importance of cultural values and meanings. 12,7 (2009)

[4] H.T. Ishii, T. Manabe, K. Ito, N. Fujita, A. Imanishi, D. Hashimoto, A. Iwasaki, Journal of Landscape Ecol Eng. Integrating ecological and cultural values toward conservation and utilization of shrine/temple forests as urban green space in japanese cities. 6, 2 (2010)

[5] G. Hofstede, G.J. Hofstede, M. Minkov, Cultures and Organizations: Software of the Mind (third edition), McGraw Hill Professional Publisher, London (2010)

[6] N. Fairclough, Analysing Discourse: Textual Analysis for Social Research, Routledge, London (2003)

[7] S. H. Schwartz, Comparaative Sociology. A theory of cultural value orientations: explication and applications. 5, 2-3 (2006) 